\title{
Alfabetizar e letrar: como percorrer o caminho, considerando teorias e práticas no plural
}

\author{
Sintia Bausen KUSTER (D) \\ Universidade Federal Fluminense (UFF)
}

\section{RESUMO}

Esta resenha que tem como foco principal discutir o processo de alfabetização e letramento, inserindo-se nas Ciências Linguísticas. Envolve a discussão de teorias e práticas relativas a esse processo, enfatizando, ainda, sobre o tão questionado método a ser utilizado nessa jornada. Ressalta a relevância do tema na atualidade e os desafios do ensino público brasileiro diante do fracasso na alfabetização e letramento, que ainda vem sendo confirmado repetidamente em avaliações com base em provas de grandes escalas. Esses resultados retratam que a grande maioria dos estudantes brasileiros ainda tem baixos níveis de leitura, de compreensão e de interpretação, ou seja, evidenciam carências relacionadas às habilidades na leitura e escrita. Decorrem, principalmente, do fato de que a preocupação $\mathrm{da}(\mathrm{o}) \mathrm{s}$ professora(e)s volta-se a ensinar o sistema de escrita alfabética, quando é preciso orientar o processo de aprendizagem e habilidade de uso da escrita alfabética para a leitura e escrita. Logo, a origem do problema está vinculada ao início dos processos de ensino e aprendizagem da língua escrita, os quais formam a base do leitor e produtor de textos.

\section{ABSTRACT}

This review has as main focus to discuss the desired literacy and proficiency process in Linguistic Sciences. It involves the discussion of theories and practices related to this process, emphasizing the much-questioned method to be used in this journey. It highlights the comparison of the theme today and the challenges of Brazilian public education in the face of failure in literacy and literacy, a fact that is still confirmed repeatedly in 


\section{REVISTA DA ABRALIN}

tests evaluated in large-scale tests. These results show that the vast majority of Brazilian students still have low levels of reading, comprehension and interpretation, which shows deficiencies related to reading and writing skills. This fact stems mainly from the concern of the teacher (s) in teaching the alphabetical writing system, when it is necessary to guide the learning process and the ability to use alphabetical writing for reading and writing. Therefore, the origin of the problem is linked to the beginning of teaching and learning the written language processes, which form the basis of the students' reading and writing texts.

PALAVRAS-CHAVE

Alfabetização. Letramento. Método.

KEYWORDS

Literacy. Proficiency. Method.

No dia 31 de julho de 2020, a doutora em didática Magda Becker Soares, professora emérita da Universidade Federal de Minas Gerais e pesquisadora do Centro de Alfabetização, Leitura e Escrita, apresentou a conferência Alfabetização e letramento: teorias e práticas (2020) no evento Abralin, realizado ao vivo, no canal do YouTube da Associação Brasileira de Linguística. Em sua fala, a professora expôs a preocupação com o ensino público brasileiro, destacando o fracasso na alfabetização e letramento, que se arrasta e é confirmado em avaliações externas da aprendizagem de crianças, jovens e adultos. Esse fracasso, segundo ela, traz em seu bojo polêmicas e divergências para o campo de estudos sobre alfabetização e letramento, vinculando-se ao início dos processos de ensino e aprendizagem da língua escrita, fase crucial na formação de leitores e produtores de textos.

Superar esse fracasso, argumenta a professora, requer compreender que sua ocorrência se dá por uma conjunção aditiva. Para explicar essa dinâmica, faz alusão à relação entre teoria e prática, enfatizando que não são teorias aplicadas à prática, nem prática aplicada a teorias. São teorias e práticas interagindo. Dessas muitas teorias desenvolvidas, derivam-se muitas práticas. Da mesma forma, alfabetização e letramento estão em relação de união, não se desvinculam entre si, caminham juntos.

$\mathrm{Na}$ ótica da professora, compreender o fracasso na alfabetização e letramento requer fincar o pé dentro da escola, por meio de um trabalho coletivo e interativo com a comunidade escolar. Nesse sentido, ela destaca o projeto que desenvolve em escolas de Lagoa Santa (MG), onde criou o Núcleo de Alfabetização e Letramento, em parceria com técnica(o)s e professora(e)s da rede municipal. O núcleo oferta formação docente com o objetivo de aproximar a reflexão teórica da realidade das salas de aula, discutir metas, trocar experiências e sistematizar conteúdos, o que, conforme seu relato, tem proporcionado resultados positivos nas práticas de alfabetização. 


\section{REVISTA DA ABRALIN}

Para avançarmos na discussão, cabe salientar o que a autora considera alfabetizar e letrar. A alfabetização, explica Soares, torna o indivíduo capaz de ler e escrever. Abarca o ensino do sistema alfabético à criança, levando-a a se apropriar de um sistema de representação dos sons da língua, da fala, em grafemas, sinais e símbolos. Significa aprender uma tecnologia, fruto de uma invenção cultural que, ao contrário da fala, adquirida espontaneamente pela criança, tem que ser aprendida por meio de maior sistematização, porque configura um sistema de representação de sons da fala a partir de sinais. Letramento, por sua vez, é a tradução, para o português, da palavra inglesa literacy, que pode significar, ainda, a condição de ser letrado.

Conforme salienta a professora, ainda que tenha relação com a alfabetização, o letramento se diferencia desta. Não basta a pessoa aprender a ler e a escrever. É necessário que o indivíduo consiga tirar conclusões, fazer inferências, escrever um texto que tenha coesão, coerência, que seja adequado ao destinatário, ou seja, que o indivíduo saiba fazer uso da leitura e da escrita a partir das demandas sociais com as quais se depara. A autora reforça que não existe uma receita pronta, sublinhando que esse processo se dá por muitas vias pavimentadas e já trilhadas, as quais devem ser consideradas para entendermos essa aprendizagem.

Por esse prisma, Soares argumenta que, em vez de ensinar o sistema de escrita alfabética, a preocupação da(o)s professora(e)s deve se voltar a orientar o processo de aprendizagem e a habilidade de uso da escrita alfabética para a leitura e escrita. E, ao fazê-lo, é preciso que a(o)s docentes levem em conta o desenvolvimento cognitivo e linguístico da criança, respeitando as evidências científicas, as quais há muito têm sido esquecidas, segundo ela. Tais evidências são observadas por teorias que, ao longo do tempo, identificam fases nos desenvolvimentos cognitivo e linguístico de apropriação do sistema de alfabetização. Dentre essas teorias, destacam-se as de Vigotsky (1935), Luria (1929), Read (1970), Bissex (1980), Gentry (1982), Ehri (1997), além de Ferreiro e Teberosky (1986).

A professora faz uma ressalva em relação ao método fônico de alfabetização. Também chamado de método fonético, tal método prioriza o ensino dos sons dos grafemas do alfabeto, começando com as letras mais simples (vogais) e caminhando até as mais complexas (consoantes), para, depois, utilizá-las na formação de sílabas e palavras. A partir de seus estudos, bem como dos realizados por outros pesquisadores, Soares destaca que o método fônico tem resultados parciais e carece de pesquisas que o analisem de forma mais aprofundada.

Ao fazer essa recomendação, a professora, inclusive, faz um alerta sobre a política de alfabetização atualmente sugerida no Brasil (Plano Nacional de Educação de Alfabetização). Conforme suas considerações, tal método, pensado há 20 anos, não encontra sentido no contexto brasileiro, porque se baseia em ortografia diferente da nossa. Em sua avaliação, o método fônico pode fazer parte da alfabetização, mas não deve ser o único a ser usado no processo (SOARES, 2016).

Entre os especialistas, segundo observou a professora, a defesa é pela dimensão do letramento, que - além da associação de grafemas e fonemas - prevê o uso social da leitura e escrita. Isso porque, sublinha Soares (2010, p. 38), “[...] aprender a ler e escrever e, além disso, fazer uso da leitura e da escrita, transformam o indivíduo, levam o indivíduo a um outro estado ou condição, sob vários aspectos: social, cultural, cognitivo, linguístico, entre outros". 


\section{REVISTA DA ABRALIN}

A concepção de aprendizagem a partir da alfabetização e letramento é adotada nas escolas de Lagoa Santa e, segundo a professora, envolve a participação de diferentes sujeitos, divergindo fundamentalmente da concepção assumida pelo Plano Nacional de Educação de Alfabetização. Assevera Soares que os pressupostos que precisamos ter para pensar em alfabetização e letramento são: quem aprende? Como se aprende? Para ela, se são as crianças, é nestas que precisamos pensar, entendendo que não existe um momento definido para seu aprendizado. Essa aprendizagem se dá ao longo de seu desenvolvimento nos âmbitos cognitivo e linguístico.

A autora destaca que os professores devem receber uma formação que os habilite a orientar adequadamente a aprendizagem dos alunos da Educação Básica, pois, em sua análise, para desenvolver o ensino da leitura e escrita, não basta conhecer sobre a língua, teorias de leitura, produção textual e teorias literárias; é preciso conhecer, também, como a criança aprende a ler e a escrever (SOARES, 2019). Há todo um processo para que a criança se forme um leitor, um produtor de textos, bem como desenvolva o gosto pela leitura. Para a autora, é necessário ter conexão entre o que ensinar e como a criança aprende. Por isso, o profissional que atua na Educação Infantil e/ou nos anos iniciais do Ensino Fundamental tem como atribuição conhecer o processo linguístico e cognitivo de apropriação da língua escrita pelas crianças matriculadas nesse nível escolar.

A conferencista também destacou a necessidade de incorporarmos a produção linguística sobre a aprendizagem da língua escrita à prática da(o)s professora(e)s. Segundo Soares, essa contribuição é fundamental, pois, em geral, tais evidências ainda estão muito restritas à área acadêmica, de modo que os pesquisadores mais estão compartilhando os resultados de seus estudos entre si, sem que eles cheguem às salas de aula. Adicionalmente, a professora mencionou várias conferências relevantes sobre o processo de alfabetização, letramento, além de outros temas.

Soares lamentou que os cursos de formação de professora(e)s, tanto a inicial, representada pelos cursos de Pedagogia, quanto a continuada, obtida em diferentes projetos, não incluam as bases cognitivas e linguísticas para a alfabetização e letramento. Ressaltou que também essas formações se restringem, geralmente, a como ensinar, quando o foco deve ser situado em como a criança aprende. Sendo assim, Soares afirma uma necessidade urgente, inadiável, de se reformular a formação da(o)s professora(e)s que atuam com crianças na Educação Infantil e nos anos iniciais do Ensino Fundamental.

As perguntas dos participantes ajudaram a enriquecer a reflexão sobre o assunto. Destas, destacou-se a que solicitava a avaliação de Soares sobre a Base Nacional Comum Curricular (BNCC). Sua crítica abarcou especificamente a área de Língua Portuguesa na Educação Infantil e séries iniciais do Ensino Fundamental. Para ela, o fato de a base dessa área ter sido ancorada na semiótica é uma desconexão com a realidade. Em sua visão, trata-se de decisão inadequada, visto que nem todas as escolas possuem tecnologias para tal. Para finalizar, a professora sugeriu que a BNCC seja formulada a partir das condições reais das crianças e escolas, para que tenha caráter personalizado, pois devemos saber o ponto ao qual queremos chegar, sobretudo, com respeito aos contextos. 


\title{
REVISTA DA ABRALIN
}

\author{
REFERÊNCIAS
}

ALFABETIZAÇÃO e letramento: teorias e práticas. Conferência proferida por Magda Soares. Produção: Associação Brasileira de Linguística. [S.1.], 31 jul. 2020, 1 vídeo (2h 26min15s). Disponível em: <https://www.youtube.com/watch?v=UnkEuHpxJPs >. Acesso em: 3 ago. 2020

BISSEX, G. L. Gnys at wrk: a child learns to write and read. Cambridge: Harvard University Press, 1980. 223p.

EHRI, L. Learning to read and learning to spell are one and the same, almost. In: PERFETTI, C.; RIEBEN, L.; FAYOL, M. (org.). Learning to spell: Research, theory, and practice across languages. Mahwah: Erlbaum, 1997. p. 237-269.

FERREIRO, E.; TEBEROSKY, A. Psicogênese da língua escrita. Tradução: Diana Myriam Lichtenstein et al. Porto Alegre: Artes Médicas, 1986. 284p.

FRITH, Uta. Beneath the surface of developmental dyslexia. In: PATTERSON, K. E.; MARSHALL, J. C.; COLTHEART, M. (eds.). Surface dyslexia: neuropsychological and cognitive analyses of phonological reading. London: Lawrence Erlbaum, 1985. p. 301-330.

LURIA, A. R. O desenvolvimento da escrita na criança. In: VYGOTSKY, L. S.; LURIA, A. R.; LEONTIEV, A. N. Linguagem, Desenvolvimento e Aprendizagem. Tradução: Maria da Penha Villalobos. São Paulo: Ícone: Editora da Universidade de São Paulo, 1998. p. 103117. Original de 1929.

READ, W. C. Children's perceptions of the sounds of English: phonology from three to six. 1970. $464 \mathrm{f}$. Tese de Doutorado. Harvard Graduate School of Education, Harvard University, Cambridge, 1970.

SOARES, Magda. A alfabetização e o letramento no Brasil. Revista Pátio Ensino Fundamental, 22 ago. 2019. Entrevista. Disponível em: <https://desafiosdaeducacao.grupoa.com.br/alfabetizacao-letramento/>. Acesso em: 15 ago. 2020.

SOARES, Magda. É preciso ter vários métodos para alfabetizar. Revista Educação, 18 out. 2016. Entrevista concedida a Rubem Barros. Disponível em: <https://revistaeducacao.com.br/2016/10/18/e-preciso-ter-varios-metodos-para-alfabetizar-afirma-especialista/>. Acesso em: 3 ago. 2020.

SOARES, Magda. Letramento: um tema em três gêneros. Belo Horizonte: Autêntica, 2010.

VYGOTSKY, L. S. A pré-história da língua escrita. In: VYGOTSKY, L. S. A formação social da mente. Tradução: José Cipolla Neto et al. São Paulo: Martins Fontes, 1984. p. 119-134. Original de 1935, publicação póstuma. 